\title{
PERANAN AGEN DALAM PENGURUSAN IZIN MASUK KAPAL ASING DI KANTOR BADAN PENGELOLA PELABUHAN BATAM (BPPB) PADA PT. ADHIGANA PRATAMA MULYA BATAM
}

\author{
${ }^{1}$ Netty Kesuma , ${ }^{2}$ Yuna Sutria, ${ }^{3}$ Shella Susilawaty \\ ${ }^{1,3}$ KPNK, ${ }^{2}$ NAUTIKA, Politeknik Adiguna Maritim Medan \\ email: yunasutria27@gmail.com
}

\begin{abstract}
Abstrak. Gambaran khususnya pada unit usaha keagenan kapal pada PT. Adighana Pratama Mulya Batam, serta kegiatan-kegiatan instansi pemerintahan yang berhubungan dengan pelayanan dan peranan agen dalam pengurusan izin masuk kapal asing di kantor Badan Pengelola Pelabuhan Batam (BPPB) yang berhubungan untuk terbitnya nota Hold Dana dan Faktur Lunas khususnya dalam hal ini di pelabuhan Batam. Penulis juga menjelaskan tentang alur proses di Badan Pengelola Pelabuhan Batam (BPPB) dimana nota Hold Dana dan Faktur Lunas ini dikeluarkan atau diterbitkan oleh Badan Usaha Pelabuhan Batam (BPPB) untuk mendapatkan Nota Hold Dana Dan Faktur Lunas diperlukan dokumen-dokumen pendukung sebagai referensi bagi pejabat BP Laut dan penulis menjelaskan alur proses yang harus dipersiapkan selaku agen pelayaran untuk mendapatkan pengurusan izin masuk kapal asing dikantor Badan Pengelola Pelabuhan Batam (BPPB) yaitu proses untuk mendapatkan terbit Nota Hold Dana dan Faktur Lunas sesuai ketentuan yang berlaku serta dilakukan dengan cara keagenan mengajukan permohonan didisposisi kapal baru, pengimputan di Ppat,Verivikasi,Hold Dana dan Faktur lunas. Perusahaan pelayaran selaku agen berhubungan langsung dengan instansi-instansi terkait, dengan adanya hubungan yang baik di pelabuhan baik itu terhadap instansi pemerintahan maupun swasta yang dilakukan oleh PT. Adhigana Pratama Mulya Batam merupakan salah satu demi tercapainya kelancaran proses pelayanan terhadap kapal. PT. Adhigana Pratama Mulya Batam juga menjalin hubungan yang baik dengan owner kapal, sehingga perusahaan dapat lebih leluasa menyampaikan informasi mengenai kapal yang sedang di ageni, baik itu mengenai kebutuhan kru kapal, dokumen-dokumen kapal hingga kebutuhan kapal lainnya.
\end{abstract}

Kata Kunci: Agen,Izin,Kapal Asing,PT.Adhigana Pratama Mulya Batam

\begin{abstract}
The description in particular on the ship agency business unit at PT. Adighana Pratama Mulya Batam, as well as the activities of government agencies related to services and the role of agents in managing entry permits for foreign ships at the Batam Port Management Agency (BPPB) office related to the issuance of Hold Funds and Invoices in full, especially in this case at the Batam port. . The author also explains about the process flow at the Batam Port Management Agency (BPPB) where the Fund Hold Note and the Settled Invoice are issued or issued by the Batam Port Business Entity (BPPB) to obtain a Fund Hold Memorandum and Settlement Invoice, supporting documents are needed as a reference for officials BP Laut and the author explained the process flow that must be prepared as a shipping agent to obtain foreign ship entry permits at the Batam Port Management Agency (BPPB) office, namely the process to obtain a Memorandum of Hold Funds and Invoices to be issued in accordance
\end{abstract}


with applicable regulations and carried out by the agency submitting an application. disposition of new ships, pick-up at Ppat, Verification, Hold Funds and Invoices paid off. The shipping company as an agent deals directly with related agencies, with a good relationship at the port both to government and private agencies carried out by PT. Adhigana Pratama Mulya Batam is one way to achieve a smooth service process for ships. PT. Adhigana Pratama Mulya Batam also maintains a good relationship with the ship owner, so that the company can more freely convey information about the ship being agencyed, be it regarding the needs of ship crews, ship documents to other ship needs.

Keywords: Agent, Permit, Foreign Ship, PT. Adhigana Pratama Mulya Batam

\section{PENDAHULUAN}

Pulau-pulau di Indonesia tersambung melalui laut-laut di antara pulaupulaunya. Laut bukan pemisah, tetapi pemersatu dari berbagai pulau, daerah dan kawasan Indonesia. Hanya melalui hubungan antar pulau, antar pantai, adalah urat nadi kehidupan sekaligus pemersatu bangsa dan negara Indonesia. Karenanya, pembangunan industri pelayaran nasional sebagai sektor strategis, perlu diprioritaskan agar dapat meningkatkan daya saing Indonesia di pasar global, karena nyaris seluruh komoditi untuk perdagangan internasional di angkut dengan menggunakan sarana dan prasarana maritim. Dari segi kegiatan yang ada di pelabuhan jelas kelihatan bahwa pelabuhan merupakan suatu unit pelayaran yang berperan dalam pertumbuhan dan perkembangan perdagangan dan perekonomian. Usaha keagenan timbul karena pertimbangan dari sebuah perusahaan pelayaran yang akan melakukan aktivitas usahanya ke pelabuhan tertentu. Aktivitas perusahaan selaku agen, khususnya dalam memberikan pelayanan terhadap kapal-kapal yang di ageni sangat erat hubungannya dengan instansiinstansi yang ada di pelabuhan. Perusahaan pelayaran mempunyai tugas dan tanggung jawab mewakili perusahaan pelayaran lainnya dalam mengageni kapalnya dan juga dalam hubungannya dengan instansi-instansi terkait.2 Untuk menjamin keselamatan pelayaran sebagai penunjang kelancaran lalu lintas kapal di laut, diperlukan adanya awak kapal yang memiliki keahlian, kemampuan dan terampil, dengan demikian setiap kapal yang akan berlayar harus diawaki dengan awak kapal yang cukup dan cakap untuk melakukan tugasnya di atas kapal sesuai dengan jabatannya dengan mempertimbangkan tonase kapal, tata susunan permesinan kapal dan daerah pelayaran. Dalam
Undang-undang peraturan kepala badan pengusahaan kawasan perdagangan bebas dan pelabuhan bebas batam No. 11 Tahun 2018 tentang petunjuk pelaksanaan jenis dan tarif layanan pada kantor pelabuhan laut badan pengusahaan kawasan perdagangan bebas dan pelabuhan bebas batam, pasal 4 butir menyatakan bahwa perusahaan pelayaran/kapten kapal harus menyampaikan pernyataan umum kedatangan kapal (General Declaration) mengacu kepada peraturan kepala badan pengusahaan batam tentang pelaksanaan system host to host pembayaran jasa kepelabuhanan dilingkungan kantor pelabuhan batam, dalam format yang disediakan kepusat pelayanan administrasi terpadu (PPAT).

\section{METODE PENELITIAN}

Dalam memperoleh data yang dibutuhkan sebagai bahan penyusunan makalah, penulis menggunakan metode guna mempermudah penulisan makalah dan agar dapat dipahami serta di mengerti oleh pembaca. Oleh karena itu selama menjalankan kegiatan Praktek Darat (PRADA) penulis telah mengumpulkan data yang diperlukan untuk kelengkapan penulisan makalah ini. Adapun metode yang digunakan penulis dalam penulisan makalah ini adalah sebagai berikut :

1. Metode Pengumpulan Data Pustaka (Library Research)

Metode ini dilakukan melalui perpustakaan untuk mendapatkan data sekunder yang bersumber dari buku pendukung yang ada 10 hubungannya dengan masalah yang di teliti untuk menunjang penelitian penulis dalam penyelesaian makalah ini.

2. Metode Pengumpulan Data Lapangan (Field Research)

a). Metode Pengamatan (Observation) : Dalam metode ini penulis secara langsung mengamati 
PT. Adhigana Pratama Mulya Batam Dalam Pengurusan Izin Masuk Kapal Asing Di Kantor Badan Pengelola Pelabuhan Batam (BPPB)

b). Metode Wawancara (Interview) : Teknik pengumpulan data dengan melakukan tanya jawab atau penelitian yang dilakukan langsung secara lisan untuk mendapatkan informasi dan keterangan-keterangan dari senior dan karyawan-karyawan

\section{HASIL DAN PEMBAHASAN}

\section{A.Sejarah Singkat Perusahaan}

.Perusahaan Pelayaran PT. Adhigana Pratama Mulya Batam berdiri pada tahun 2013 yang didirikan oleh bapak Elimansyah Hia sebagai komisaris utama dan pemegang saham terbesar pada perusahaan yang bekerjasama dengan bapak Rezky Putra Effendy sebagai komisaris dua dan bapak Rhali Trida Cemastian Dhana sebagai komisaris tiga. PT Adhigana Pratama Mulya adalah perusahaan pelayaran yang bergerak dibidang jasa keagenan kapal sebagai General Agent dan Sub Agent. Yang dimana General Agent sebagai perantara antara Owner dan Sub Agent yang diageni oleh perusahaan PT Adhigana Pratama Mulya, sedangkan Sub Agent PT Adhigana Pratama Mulya menangani khusus bermuatan LPG/C dan oil tanker yang masuk pada wilayah Batam dan perairan Pulau Nipah, saat ini PT Adhigana Pratama Mulya memiliki empat cabang agen yang tersebar diseluruh Indonesia antara lain Tanjung Balai Karimun, Palu, Kuala Tanjung dan Belawan. Seiring berjalannya waktu terjadi peningkatan penunjukan kapal oleh pihak Owner, penambahan fasilitas dan perekrutan karyawan diperkirakan akan terus bertambah. PT Adhigana Pratama Mulya Batam berkantor pusat di Batam dan memiliki empat cabang di Indonesia antara lain Tanjung Balai Karimun, Palu, Kuala Tanjung dan Belawan. Adapun lokasi kantor Taruna praktek yaitu bertempat di Jalan Jendral Sudirman, Ruko Dermaga Culinary Paradise Blok RJ Nomor 05 Bukit Indah Sukajadi, Batam, Kepulauan Riau - Indonesia.

\section{B. Aktivitas Keagenan Dalam Penanganan Dokumen Kapal}

\section{a. Proses Penanganan Dokumen Kapal Masuk (Clearance In)}

Untuk setiap kapal yang diageni, perusahaan pelayaran yang bertindak sebagai agen harus melakukan registrasi atau izin masuk kapal di suatu wilayah atau pelabuhan yang disinggahi kapal tersebut. Untuk kegiatan ini instansi yang terkait (yang dihubungi) adalah :

\section{1) Bea Cukai}

Pada saat sebelum kapal tiba, perusahaan pelayaran yang bertindak sebagai agen setelah menerima copy outward manifest dari pelabuhan asal yang kemudian akan dilakukan registrasi inward manifest yang akan di submit kepada petugas bea cukai. Selain melampirkan Outward Manifest dari pelabuhan asal, pihak agen juga melampirkan copy last port clearance (surat persetujuan berlayar), crew list. Kemudian setelah itu perusahaan pelayaran selaku agen akan memperoleh dokumen berupa inward manifest.

\section{2) Badan Pengusahaan Batam/BP}

Batam Beberapa hari sebelum kapal tiba/24 jam sebelum kedatangan kapal PT. Adhigana Pratama Mulya Batam selaku agen pelayaran meregister kedatangan kapal yang diageninya dalam bentuk Form PUK (Pernyataan Umum Kapal) di Kantor Pelabuhan Batam, kemudian setelah itu perusahaan pelayaran selaku agen akan memperoleh dokumen berupa form rencana kedatangan dan keberangkatan kapal dan bukti hold dana

3) Kepanduan PT.Pelabuhan Indonesia (Pelindo)

Untuk proses pemakaian pandu kapal harus memiliki GT lebih dari 500 ke atas. Jika GT lebih dari 500 ke atas maka selaku agen pelayaran mengajukan permohonan dan form pandu ke pihak pelindo agar disetujui, kemudian setelah itu perusahaan pelayaran selaku agen akan memperoleh dokumen berupa form pandu yang telah disetujui disertai dengan cap atau stampel sebagai bukti persetujuan.

4) Kesyahbandaran

Untuk proses registrasi kapal kepada pejabat kesyahbandaran dengan mensubmit pemberitahuan rencana kedatangan kapal yang kemudian akan diterbitkan pernyataan umum kapal (PUK) dengan melampirkan copy last port clearance (surat izin berlayar, crew list, outward manifest) dan data-data kapal seperti copy surat laut dan surat ukur. Pada saat kapal tiba di pelabuhan tujuan, perusahaan pelayaran yang bertindak sebagai agen mengambil seluruh dokumen asli di kapal untuk proses registrasi memorandum, pejabat syahbandar memeriksa seluruh dokumen asli kapal seperti : Last port clearance (surat izin berlayar, crew list, outward manifest) serta sertifikat kapal, kemudian setelah itu perusahaan 
pelayaran selaku agen akan memperoleh nomor registrasi kapalnya yang masuk kewilayah pelabuhan batam.

\section{5) Imigrasi}

Untuk pejabat imigrasi perlu dilakukan pemeriksaan terhadap dokumen awak kapal (crew) seperti kelengkapan passport dan buku pelaut (seaman book). Untuk paspor di periksa masa berlaku serta cap imigrasi dari pelabuhan asal (apabila kapal datang dari luar perairan Indonesia) dan untuk buku pelaut (seaman book) di periksa formality sign on nya, kemudian setelah itu perusahaan pelayaran selaku agen akan memperoleh cap imigrasi kedatangan di paspor kru kapal.

6) Karantina

Pada saat kapal tiba dipelabuhan pejabat karantina wajib memeriksa keadaan kapal, apakah kapal bebas dari hama tikus atau hama lainnya yang dapat menimbulkan 20 penyakit bagi crew atau tidak. Jika terdapat hama penyakit, maka kapal tersebut wajib dilakukan fumigasi, kemudian setelah itu perusahaan pelayaran selaku agen akan memperoleh dokumen berupa sertifikat izin karantina (free pratique) Adapun hal-hal yang perlu dipersiapkan dalam proses kedatangan kapal adalah sebagai berikut:

1). Mengajukan PUK (pernyataan umum kapal) ke kantor pelabuhan.

2). Melaporkan rencana kedatangan kapal kepada kantor Imigrasi dan Karantina jika kapal berasal dari Luar Negeri.

3). Mengajukan permohonan pemanduan kapal ke kantor Pelindo jika kapal memiliki GT lebih dari 500 ke atas.

4). Mengajukan LKK (laporan kedatangan kapal) ke kantor Syahbandar.

5). Mengajukan RKSP (rencana kedatangan sarana pengangkut) ke kantor Bea dan cukai.

6). Mengajukan Inward Manifest (BC 1.1) ke kantor Bea dan Cukai.

7). Proses penyandaran kapal di Dermaga.

8). Clearance In Imigrasi dan Karantina dilakukan hanya untuk kapal yang berasal dari Luar Negeri.

\section{b. Proses Penanganan Kapal Keluar (Clearance Out)}

Untuk proses keberangkatan kapal (clearance out), perusahaan pelayaran yang bertindak sebagai agen mempersiapkan seluruh kelengkapan dokumen atau port clearance (surat izin berlayar, crew list dan outward manifest), memastikan kelengkapan serta validasi dari seluruh sertifikat kapal, serta kelengkapan dokumen crew (paspor dan buku pelaut). Adapun hal-hal yang perlu dipersiapkan dalam proses keberangkatan kapal adalah sebagai berikut : 1) Mengajukan LK3 (laporan kedatangan dan keberangkatan kapal) ke kantor syahbandar. 2) Mengajukan SPKK (surat pemberitahuan keberangkatan kapal) ke kantor Satker (satuan kerja). 3) Mengajukan Outward Manifest ke kantor Bea dan Cukai. 4) Clearance Out Karantina, Syahbandar, dan Bea dan Cukai dan Imigrasi dilakukan apabila kapal akan berangkat ke Luar Negeri. 5) Mengantar Dokumen kapal ke kapal yang akan berangkat. 6) Proses pengeluaran kapal dari jetty dermaga tempat kapal sandar.

\section{Jenis - Jenis Sertifikat Kapal \\ a. Sertifikat Kapal}

Sertifikat kapal ialah sebagian dari persyaratan sebuah kapal yang harus dilengkapi sesuai dengan ketentuan yang berlaku. Berdasarkan Peraturan Pemerintah RI No. 51 Tahun 2002 Tentang Perkapalan pada Bab VI Bagian Kedua tentang Pemeriksaan, Pengujian dan Sertifikasi : Pasal 55 ayat (1) Setiap kapal yang berdasarkan hasil pengujian dan pemeriksaan sebagaimana dimaksud dalam pasal 53 dan pasal 54 memenuhi persyaratan keselamatan kapal, diberikan sertifikat keselamatan kapal. Ayat (2) Setiap kapal yang berlayar diperairan Indonesia harus memiliki sertifikat keselamatan kapal, keselamatan radio dan garis muat. Ayat (4) kapal harus memiliki sertifikat sebagaimana dimaksud dalam ayat (2) sesuai dengan daerah pelayarannya. Ayat (5) kapal untuk daerah pelayaran semua lautan atau pelayaran Internasional harus memiliki sertifikat sesuai dengan ketentuan Konvensi Internasional. Ayat (6) sertifikat sebagaimana dimaksud dalam ayat (2) dan (3) berdasarkan jenis pemeriksaan sebagaimana dimaksud dalam pasal 54 di golongkan sebagai : a. Sertifikat sementara, b. Sertifikat pertama, c. Sertifikat pembaharuan. Pasal 56 ayat (1) sertifikat kapal yang dikelurkan oleh pejabat yang berwenang dari negara asing, dapat diakui oleh Pemerintah jika persyaratan untuk mendapatkannya dinilai sekurang-kurangnya sepadan dengan persyaratan yang diatur dalam Peraturan Pemerintah ini. Ayat (2) selain sertifikat kapal sebagaimana dimaksud dalam ayat (1) sertifikat terhadap komponen kapal yang dikeluarkan oleh badan klasifikasi yang diakui, dapat dipakai sebagian dokumen pemeriksaan kapal.

Adapun jenis-jenis sertifikat kapal di bawah ini yaitu : 
a). Surat Laut (Certificate of Registry).

Surat laut /Certificate of Registry yaitu sertifikat yang menyatakan tanda kebangsaan kapal yang diberikan oleh Pemerintah Negara. Kapal tersebut berhak atas perlindungan hukum dari negara tersebut dan kapal berhak mengibarkan bendera dari negara dimana kapal itu didaftarkan.

b). Surat Ukur (International Tonnage Certificate).

Surat ukur / International Tonnage Certificate yaitu sertifikat yang menyatakan rincian (detail) mengenai ukuran/tonnage kapal, yang terdiri dari dari volume keseluruhan, panjang kapal, lebar kapal, isi kotor (gross registry tonnage), isi bersih (net registry tonnage).

c). Sertifikat Lambung Timbul Kapal (International Load Line Certificate).

Sertifikat Lambung Timbul Kapal / International Load Line Certificate yaitu sertifikat yang menerangkan tentang ketetapan lambung timbul kapal yang boleh timbul di atas permukaan air laut dengan batas maksimum dan minimum kapal.

d). Sertifikat Keselamatan Konstruksi Kapal Barang (Cargo Ship Safety Construction Certificate).

Sertifikat Keselamatan Konstruksi Kapal Barang / Cargo Ship Safety Construction Certificate yaitu sertifikat yang menyatakan konstruksikonstruksi kapal, yang terdiri dari badan kapal, mesin, perlengkapan dan lain-lain mengenai keamanan yang telah layak laut.

e). Sertifikat Keselamatan Perlengkapan Kapal Barang(Cargo Ship Safety Equipment Certificate)

Sertifikat Keselamatan Perlengkapan Kapal Barang / Cargo Ship Safety Equipment Certificate yaitu sertifikat yang menyatakan perlengkapanperlengkapan di atas kapal, diterbitkan setelah pemeriksaan alat-alat penolong, keselamatan, dan perlengkapan lainnya.

f). Sertifikat Keselamatan Radio Kapal Barang (Cargo Ship Safety Radio Certificate).

Sertifikat Keselamatan Radio Kapal Barang / Cargo Ship Safety Radio Certificate yaitu sertifikat yang menerangkan bahwa kapal telah dilengkapi pesawat penerima dan pemancar radio sesuai dengan syarat tertentu.

g). Sertifikat Kelengkapan Minimum Awak Kapal (Minimum Safe Manning Certificate).

Sertifikat Kelengkapan Minimum Awak Kapal / Minimum Safe Manning Document yaitu sertifikat yang menerangkan jumlah perwira dan anak buah kapal lainnya berserta jabatan yang telah ditentukan.

h). Sertifikat Manajemen Keselamatan (Safety Management Certificate).
Sertifikat Manajemen Keselamatan / Safety Management Certificate yaitu sertifikat yang diterbitkan untuk membuktikan bahwa perusahaan dan manajemen di atas kapal bekerja/terselenggara sesuai dengan sistem keselamatan yang telah disahkan.

i). Dokumen Kepatuhan (Document of Compliance).

Dokumen kepatuhan / Document of Compliance yaitu dokumen yang diterbitkan oleh pemerintah untuk suatu perusahaan yang telah memenuhi persyaratan ISM Code.

j). Sertifikat Pencegahan Polusi Minyak Internasional (International Oil Pollution Prevention Certificate).

Sertifikat Pencegahan Polusi Minyak Internasional / International Oil Pollution Prevention Certificate yaitu sertifikat yang menyatakan bahwa kapal tersebut memiliki peralatan mencegah terjadinya pencemaran polusi dari minyak selama kapal dalam pengoperasian.

$\begin{array}{cccc}\text { k).Sertifikat } & \text { Pencegahan } & \text { Polusi } & \text { Kotoran } \\ \text { Internasional } & \text { (International } & \text { Sewage } & \text { Pollution }\end{array}$ Prevention Certificate).

Sertifikat Pencegahan Polusi Kotoran Internasional / International Sewage Pollution Prevention Certificate yaitu sertifikat yang menyatakan bahwa kapal tersebut memiliki peralatan mencegah terjadinya pencemaran polusi dari kotoran selama kapal dalam pengoperasian.

1). Sertifikat Pencegahan Polusi Udara Internasional (International Air Pollution Prevention Certificate).

Sertifikat Pencegahan Polusi Udara Internasional / International Air Pollution Prevention Certificate yaitu sertifikat yang menyatakan bahwa kapal tersebut memiliki peralatan mencegah terjadinya pencemaran polusi dari udara selama kapal dalam pengoperasian.

m). Sertifikat Sistem Anti Fouling Internasional (International Anti Fouling System Certificate).

Sertifikat Sistem Anti Fouling Internasional / International Anti Fouling System Certificate mengacu pada perangkat lapisan, cat, pengobatan permukaan atau digunakan pada kapal untuk mengontrol/mencegah penempelan organisme yang tidak digunakan.

n.) Sertifikat Keamanan Kapal Internasional (International Ship Security Certificate). S

Sertifikat Keamanan Kapal Internasional / International Ship Security Certificate yaitu sertifikat yang menyatakan bahwa kapal telah mempunyai keamanan dan awak kapal dalam pengoperasian.

o). Sertifikat Kelas (Certificate of Classification).

Sertifikat Kelas / Certificate of Classification yaitu sertifikat yang menerangkan bahwa kapal 
termasuk jenis kelas yang sesuai dengan konstruksi kapal dan perlengkapan yang lain. Sertifikat kelas dikeluarkan oleh badan perusahaan tertentu yang diakui oleh Direktorat Jenderal Perhubungan Laut diantaranya BKI (Biro Klasifikasi Indonesia), ABS (American Bureau of Shipping), DNV (Det Norske Veritas).

p). Port State Control (PSC). Port State Control (PSC)

Pemeriksaan kapal asing dipelabuhan nasional untuk memverifikasi bahwa kondisi kapal dan peralatan sesuai dengan persyaratan internasional dan menyatakan bahwa kapal diawaki dan dioperasikan sesuai dengan aturan-aturan.

q). Surat Persetujuan Berlayar Dari Pelabuhan Sebelumnya (Last Port Clearance).

Surat Persetujuan Berlayar Dari Pelabuhan Sebelumnya / Last Port Clearance yaitu surat yang menyatakan bahwa kapal telah di periksa di pelabuhan yang terakhir disinggahi dan layak untuk melakukan perjalanan ke pelabuhan berikutnya.

r). Buku Kesehatan (Healthy Book).

Buku Kesehatan / Healthy Book atau sering disebut Buku Hijau yaitu buku yang dikeluarkan oleh Kantor Kesehatan Pelabuhan dan Karantina yang menyatakan bahwa kapal dan kru kapal dalam kondisi sehat.

s). Sertifikat Sanitasi Kapal ( Ship Sanitation Control Exemption).

Sertifikat Sanitasi Kapal / Ship Sanitation Control Exemption yaitu sertifikat yang menyatakan bahwa kapal bebas dari penyakit seperti hama tikus. t. Inflatable Liferaft Certificate. Inflatable Liferaft Certificate yaitu sertifikat yang menerangkan bahwa kapal dilengkapi dengan alat-alat keselamatan seperti pelampung, baju renang, rakit penyelamat atau skoci. u). Fire Extinguisher Certificate. Fire Extinguisher Certificate.

Sertifikat yang menerangkan bahwa kapal dilengkapi alat-alat keselamatan dari kebakaran, seperti racun api.

\section{Peranan Agen Dalam Pengurusan Izin Masuk Kapal Asing Di Kantor Badan Pengelola Pelabuhan Batam (BPPB) Pada PT. Adhigana Pratama Mulya}

Badan Pengelola Pelabuhan Batam (BPPB) adalah badan usaha pengelola pengurusan dibatam, prosedur yang dilakukan sebelum kapal tiba / 24 jam sebelum kedatangan kapal PT.Adhigana Pratama Mulya Batam selaku agen pelayaran melakukan Register kapal baru dalam bentuk Form Permohonan Kapal Baru atau Perubahan data kapal agar masuk kesystem Badan Pengelola Pelabuhan Batam (BPPB) Adapun lampiran untuk melakukan Register kapal baru yaitu :

\section{a). Form Permohonan Kapal Baru}

Form tersebut berisikan untuk mengisi data-data kapal yang akan masuk diwilayah batam. Maka pihak PT.Adhgina Pratama Mulya Batam selaku agen mengisi dan meregister kapal yang akan masuk ke batam.

b). Surat Ukur (International Tonnage Certificate). Surat ukur / International Tonnage Certificate

Sertifikat yang menyatakan rincian (detail) mengenai ukuran/tonnage kapal, yang terdiri dari dari volume keseluruhan, panjang kapal, lebar kapal, isi kotor (gross registry tonnage), isi bersih (net registry tonnage). Surat ukur yang dilampirkan untuk salah satu lampiran permohonan kapal baru dimana surat ukur tersebut dilampirkan dari kapal yang akan masuk di batam.

c). Surat Laut (Certificate of Registry). Surat laut / Certificate of Registry

Sertifikat yang menyatakan tanda kebangsaan kapal yang diberikan oleh Pemerintah Negara. Kapal tersebut berhak atas perlindungan hukum dari negara tersebut dan kapal berhak mengibarkan bendera dari negara dimana kapal itu didaftarkan. Surat laut yang dilampirkan untuk salah satu lampiran permohona kapal baru dimana surat laut tersebut dilampirkan dari kapal yang akan masuk dibatam.

\section{d). Materai 9000}

Memakai materai 9000 untuk bertujuan bahwasanya pernyataan data kapal tersebut benar dan dapat dipertanggung jawabkan dan ditempelkan dipermohonan Form Kapal Baru.

Setelah kapal berhasil diapprove oleh pihak BPPB didaftarkan, maka pihak agen dapat menginput kapal yang akan datang untuk mendapatkan dan membayar tagihan kegiatan yaitu Nota Hold dana dan Nota Faktur Lunas. Alur keagenan di BPPB (Badan Pengelola Pelabuhan Batam) untuk melakukan Hold Dana dan Faktur Lunas harus melalui tahap-tahap pengimputan dan pengecekan.

Adapun alur agar terbit Nota Faktur Lunas sebagai berikut :

a). Form Ceklis Sebelum melakukan pengimputan maka pihak agen mengisi data form ceklis. 
b). PPAT (Pusat Pelayanan Adminitrasi Terpadu) Kapal-kapal yang masuk atau berada dikawasan batam wajib melakukan pengimputan data data kapal di PPAT.

c). Verivikasi (Kasi \& Kabid) Setelah melakukan pengimputan di PPAT maka pihak selaku agen meneruskan untuk meletak data yg telah diinput diverivikasi untuk melakukan mengecekan sebelum di cetak nota Hold Dana.

d). Nota Hold Dana Nota Hold Dana adalah dana yang dibekukan atau ditahan dibank yang dimiliki perusahaan bersangkutan untuk membayar tagihan kegiatan dipelabuhan atau kawasan batam

e). Realisasi Satker (Satuan Kerja) Realisasi adalah kegiatan kapal yang real, dimana jam labuh,tambat,manifest bongkar atau muat yang sebenarnya.

f) Verivikasi (Kasi \& Kabid) Setelah melakukan Realisasi disatker maka pihak selaku agen meneruskan untuk meletak data yg telah diinput diverivikasi untuk melakukan mengecekan sebelum di cetak Nota Faktur Lunas.

g). Nota Faktur Lunas Nota Faktur Lunas adalah dana yang dibayar sesuai kegiatan yang sebenarnya yang akan dibayar atau ditagih. Setelah Nota Faktur Lunas didapatkan maka itu adalah sebagai salah satu lampiran untuk LKKK (LK3). Peraturan Kepala Badan Pengusahaan Kawasan Perdagangan Bebas Dan ,,....Pelabuhan Bebas Batam Nomor 11 Tahun 2018 Tentang Ketentuan Umum

\section{KESIMPULAN}

Adapun Dalam Proses Izin Masuk Kapal Asing pada Badan Pengelola Pelabuhan Batam (BPPB) dilakukan dengan cara pemilik kapal / keagenan mengajukan permohonan di Badan Pengelola Pelabuhan Batam (BPPB), dan diperlukan dokumen-dokumen pendukung untuk pengimputan data kapal. Tentang alur proses di Badan Pengelola Pelabuhan Batam (BPPB) dimana nota Hold Dana dan Faktur Lunas ini dikeluarkan atau diterbitkan oleh Badan Usaha Pelabuhan Batam (BPPB) untuk mendapatkan Nota Hold Dana Dan Faktur Lunas diperlukan dokumendokumen pendukung sebagai referensi bagi pejabat BP Laut dan penulis menjelaskan alur proses yang harus dipersiapkan selaku agen pelayaran untuk mendapatkan pengurusan izin masuk kapal asing dikantor Badan Pengelola Pelabuhan Batam (BPPB) yaitu proses untuk mendapatkan terbit Nota Hold Dana dan Faktur Lunas sesuai ketentuan yang berlaku serta dilakukan dengan cara keagenan mengajukan permohonan didisposisi kapal baru, pengimputan di Ppat,Verivikasi,Hold Dana dan Faktur lunas. Perusahaan pelayaran selaku agen berhubungan langsung dengan instansi-instansi terkait, dengan adanya hubungan yang baik di pelabuhan baik itu terhadap instansi pemerintahan maupun swasta untuk salah satu demi tercapainya kelancaran proses pelayanan terhadap kapal pihak agen juga menjalin hubungan yang baik dengan owner kapal, sehingga perusahaan dapat lebih leluasa, menyampaikan informasi mengenai kapal yang sedang di ageni, baik itu mengenai kebutuhan kru kapal, dokumen-dokumen kapal hingga kebutuhan kapal lainnya.

\section{DAFTAR PUSTAKA}

Dr. D.A Lasse. Manajemen Kepelabuhanan. Jakarta : RajaGrafindo Persada, 2016

Peraturan Menteri Kesehatan Republik Indonesia Nomor 40 Tahun 2015 Tentang Sertifikat Sanitasi Kapal Dengan Rahmat Tuhan Yang Maha Esa Menteri Kesehatan Republik Indonesia Tentang Ketentuan Umum Pasal 2

Peraturan Kepala Badan Pengusahaan Kawasan Perdagangan Bebas Dan Pelabuhan Bebas Batam Nomor 11 Tahun 2018 Tentang Ketentuan Umum

Keputusan Menteri Perhubungan Republik Indonesia Nomor Kp 775 Tahun 2018 Tanggal 4 Mei 2018 Tentang Penetapan Alur-Pelayaran, Sistem Rute, Tata ,,,,,,,Cara Berlalu Lintas, Dan Daerah Labuh Sesuai Dengan Kepentingannya Di Pelabuhan Batam Pada Terminal Batu Ampar Dan Terminal Sekupang 